\title{
Erratum to: Estimation of dune celerity and sand flux in part of West Rajasthan, Gadra area of the Thar Desert using temporal remote sensing data
}

\author{
Lydia Sam $^{1} \cdot$ Nidhi Gahlot $^{1}$ • B. G. Prusty ${ }^{1}$
}

Published online: 6 June 2016

(C) Saudi Society for Geosciences 2016

Erratum to: Arab J Geosci (2015) 8:295-306

DOI 10.1007/s12517-013-1219-4

The original version of this article contained errors in Fig. 1.

This erratum shows the correct study area of Fig. 1 found on page 297 in Volume 8, Issue 1 of the journal and also the correct legend/caption to this figure.

Presented in the following is the correct image and caption.

The online version of the original article can be found at http://dx.doi.org/ 10.1007/s12517-013-1219-4.

Lydia Sam

lydsam36@gmail.com

1 Defence Terrain Research Laboratory, DRDO, Metcalfe House, Civil

Lines, New Delhi, India 


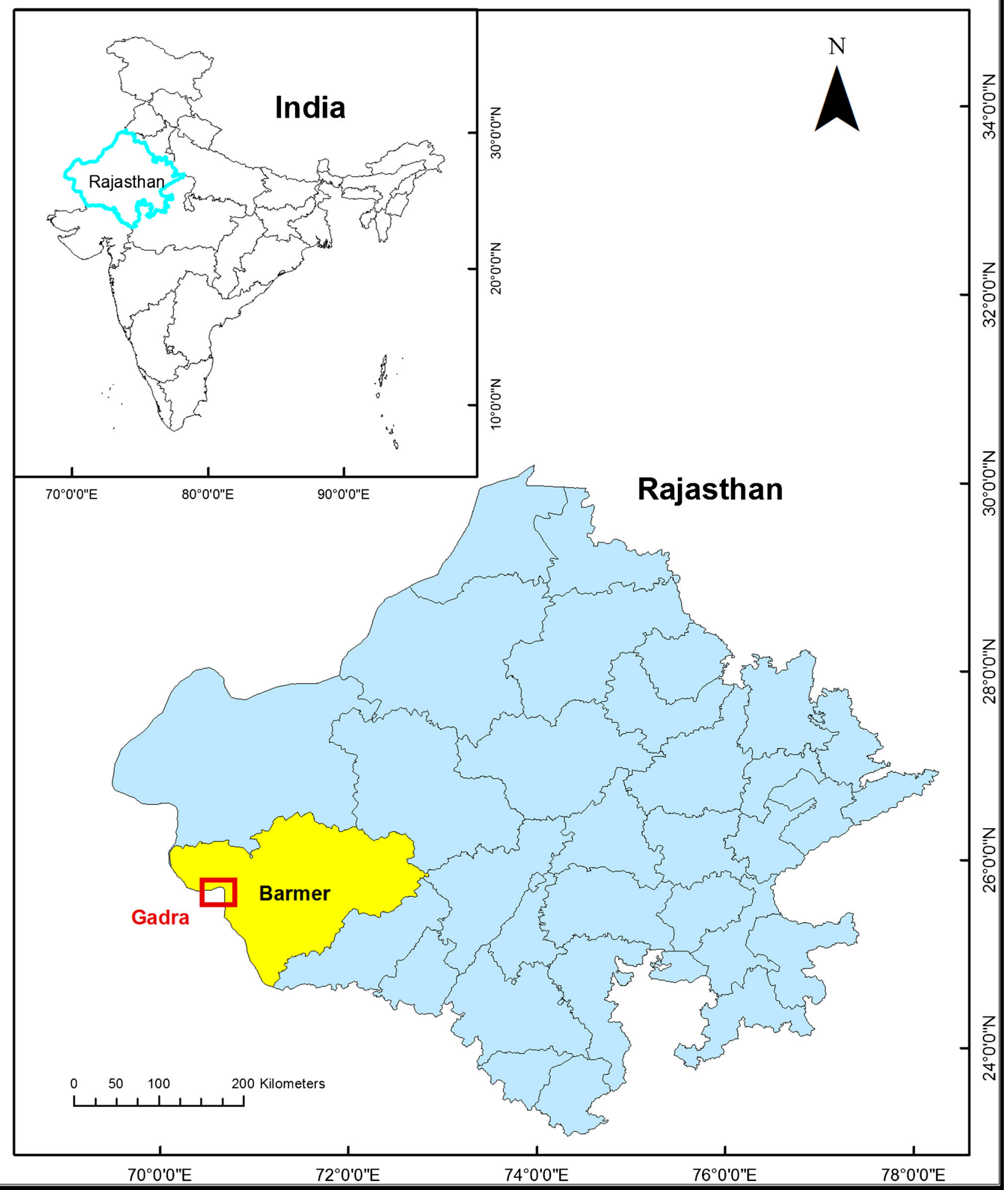

Fig. 1 Location map for Gadra in Barmer District, Rajasthan, India. The inset map is not up to scale and is only for reference 